\title{
Sequential determination of arsenite and arsenate by ion chromatography
}

\author{
Zong-li Li ${ }^{\text {a }}$, Shi-fen Mou ${ }^{\mathrm{a}, *}$, Zhe-ming Ni ${ }^{\text {a }}$, John M. Riviello ${ }^{b}$ \\ ${ }^{a}$ Research Center for Eco-Environmental Sciences of Academia Sinica, P.O. Box 2871, Beijing 100085. C'hina \\ ${ }^{b}$ Dionex Corporation, 1228 Titan Way, P.O. Box 3603, Sunnyvale, CA, USA
}

Received 19 July 1994; revised 22 December 1994; accepted 30 December 1994

\begin{abstract}
A procedure for the sequential determination of arsenite [As(III)] and arsenate [As(V)] based on electrochemical detection for $\mathrm{As}(\mathrm{III})$ and spectrophotometric detection for $\mathrm{As}(\mathrm{V})$ following ion chromatographic separation was developed. The color-developing system was based on the ion-association complex formed by heteropolymolybdoarsenic acid with bismuth in the presence of Triton X-100. Experimental conditions for electrochemical detection and color-developing conditions were optimized for As(III) and As(V), respectively. The optimal applied potential for electrochemical detection of As(III) was $+0.35 \mathrm{~V}$ and the wavelength for spectrophotometric detection of $\mathrm{As}(\mathrm{V})$ was $700 \mathrm{~nm}$. By using an eluent of $2.0 \mathrm{mM}$ sodium hydrogencarbonate $-5.5 \mathrm{mM}$ sodium carbonate with a $175 \mu$ l sample loop for ion chromatographic separation, the detection limits, which are defined as the concentrations that give the peak intensity twice the baseline noise, are found to be $2.9 \mu \mathrm{g} / 1$ for $\mathrm{As}(\mathrm{III})$ and $13 \mu \mathrm{g} / \mathrm{l}$ for $\mathrm{As}(\mathrm{V})$, respectively. The spiked waste water samples were analyzed and recoveries were found to be $97.5-104 \%$ for As(III) and $93.5-103 \%$ for As(V), respectively.
\end{abstract}

Keywords: Ion chromatography; Spectrophotometry; Arsenic

\section{Introduction}

The speciation of toxic elements is very important not only in identifying toxic levels of elements, but also for gaining insight into its biochemical cycling. The harmful effects of any toxic element must be ascribed to its distinct molecular forms and not to the element. This is especially true for arsenic. The

\footnotetext{
* Corresponding author.
}

toxicity of arsenic is known to depend on its chemical form. Arsenite [As(III)] is the most toxic of the water-soluble species, arsenate [As(V)] is also relatively toxic, whereas the methylated forms, methylarsonic acid (MMA) and dimethylarsinic acid (DMA), are much less toxic [1]. Therefore the methods which determine the total amount of arsenic in cnvironmental samples do not satisfy the demand of studies for environmental protection.

A variety of procedures have been published for the determination of inorganic and organic species of As $[2,3]$, among which ion chromatography (IC) is 
an attractive analytical technique for element speciation because it can separate both inorganic and organic charged species in addition to free ions. Many different procedures determining arsenic compounds by using ion chromatography have been reported. Steiber and Merrill [4] and Hansen et al. [5] determined arsenic as the oxo anion by ion chromatography. These procedures involved oxidation of the As(III) to As(V) in an aqueous solution before measurement. Hoover and Yager [6] measured arscnatc in drinking water, surface water, and groundwater sources by multidimensional ion chromatography, in which the selected portion of the ion chromatogram was collected, after suppression, on a concentrator column and reinjected at the original chromatographic conditions. Butler [7] separated As(III) and As(V) by ion-exclusion chromatography, and detected both of them by UV detection at $200 \mathrm{~nm}$, but the sensitivity obtained was poor. Amperometric detection with a platinum-wire electrode at an applied potential of $+1.00 \mathrm{~V}$ allows As(III) to be determined down to $0.012 \mu \mathrm{M}$, and total inorganic arsenic was determined as As(III) after reduction of As(V) by sulphur dioxide [7]. Tan and Dutrizac [8-11] determined As(III) and As(V) in metallurgical processing media simultaneously by IC with electrochemical and conductivity detectors and obtained the detection limits of $5 \mu \mathrm{g} / \mathrm{l}$ for As(III) and $22 \mu \mathrm{g} / 1$ for As(V), respectively, where the detection limit was defined as the concentration that gave a peak intensity twice the baseline noise. In recent years, liquid chromatography (LC) and ion chromatography coupled with element specific detectors have been developed, involving atomic absorption spectrometry (AAS) [12,13], graphitc furnace atomic absorption spectrometry (GFAAS) [14-16] or inductively coupled argon plasma emission spectrometry (ICP) $[17-20]$ and inductively coupled plasma mass spectrometry (ICP-MS) [21,22]. The hyphenated methods incorporate the high sensitivity of elementspecific detectors into the powerful separation of a chromatographic method thus making them an attractive analytical methods for element speciation. However, these techniques require expensive and sophisticated instruments which are not readily available in all laboratories.

The aim of our present study is to develop a relatively simple and precise method for the sequen- tial determination of As(III) and As(V) using amperometric detection for As(III) and spectrophotometric detection for $\mathrm{As}(\mathrm{V})$ following ion chromatographic separation on an AS4A-SC anion exchange column. The use of heteropoly molybdoarsenic acid with bismuth for $\mathrm{As}(\mathrm{V})$ determination as a post-column reaction of a ion chromatography is reported for the first time. Spiked waste water samples were analyzed and the results were satisfactory.

\section{Experimental}

\subsection{Apparatus}

A Dionex Model DX-300 ion chromatography equipped with a $175 \mu \mathrm{l}$ sample loop, Dionex AG4A$\mathrm{SC}$ guard column $(50 \times 4 \mathrm{~mm}$ i.d.) and Dionex AS4A-SC separation column $(250 \times 4 \mathrm{~mm}$ i.d. $)$ were used. The detectors were a Dionex pulsed electrochemical detector Model II (PED-II) and a Dionex variable wavelength detector Model II (VDM-II). The former contains three types of detection: amperometry, conductivity and integrate amperometry.

For the sequential determination of inorganic arsenic species, a combination of the detectors has been developed. As shown in Fig. 1, As(III) was

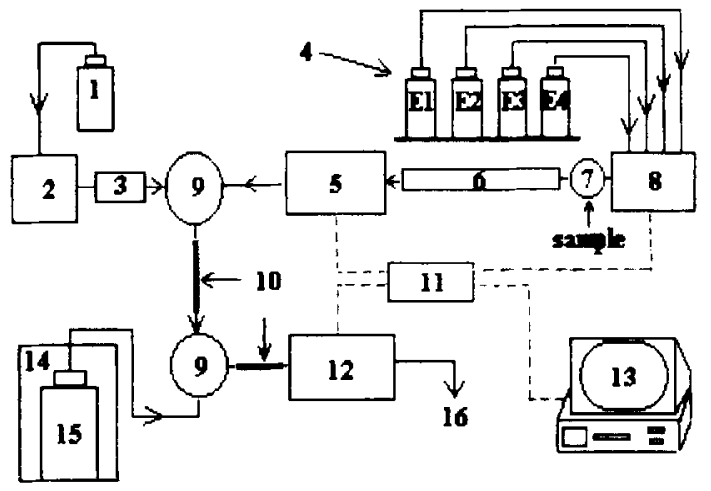

Fig. 1. Schematic of system configuration. $1=$ Color reagent; $2=$ reagent delivery pump; $3=$ pulse damper; $4=$ eluents; $5=$ amperometric cell; $6=$ separation column; $7=$ sample injection valve; $8=$ pump; $9=$ three-way liquid mixing tees; $10=$ reaction coils; 11 = computer interface; 12 = spectrophotometric detector; $13=$ computer; $14=$ pneumatic reagent dilivery; $15=1.2 \%$ Triton $\mathrm{X}-100 ; 16=$ waste. 
detected by electrochemical detector and As(V) by spectrophotometric detector. The experiments were run at a $1.5 \mathrm{ml} / \mathrm{min}$ eluent flow-rate using a pre-degassed solution of $2.0 \mathrm{mM}$ sodium hydrogencarbonate $-5.5 \mathrm{mM}$ sodium carbonate $(\mathrm{pH} 10.5)$. For the VDM-II detector, the wavelength used for analysis was $700 \mathrm{~nm}$. For the PED-II detector, the amperometric type was selected and an applied potential of $+0.35 \mathrm{~V}$ was used for the electrochemical measurement for As(III). A platinum electrode served as the working electrode. It was occasionally cleaned by polishing with fine alumina paste.

All the operations were controlled by a Dionex AL-450 chromatography workstation. Output data from the two detectors can be recorded and stored in the computer. Chromatograms obtained can be simultaneously displayed on the computer when the ion chromatography is running and the scales can be changed conveniently anytime.

The preliminary spectrophotometric experiments were done using a Shimadzu UV-120-02 spectrophotometer with $1 \mathrm{~cm}$ quartz cells.

\subsection{Reagents}

\section{Arsenic standard solutions}

A primary As(III) standard (1000 $\mathrm{mg} / 1)$ was prepared from arsenic trioxide $\left[\mathrm{As}_{2} \mathrm{O}_{3}, \mathrm{JMC} 642\right.$ specpure, Johnson Mattey] and a primary As(V) standard was prepared by oxidizing the primary As(III) standard with aqua regia as reported by Tan and Dutrizac [8,9]. Secondary As(V) standard was prepared from sodium arsenate $\left[\mathrm{Na}_{3} \mathrm{AsO}_{4} \cdot 12 \mathrm{H}_{2} \mathrm{O}\right]$. It was standardized against the primary $\mathrm{As}(\mathrm{V})$ solution by ion chromatography [9].

\section{Color-developing reagent}

$0.94 \mathrm{~g}$ of ammonium molybdate $\left[\left(\mathrm{NH}_{4}\right)_{6} \mathrm{Mo}_{7} \mathrm{O}_{24}\right.$ $\left.4 \mathrm{H}_{2} \mathrm{O}, \mathrm{AR}\right]$ was dissolved in $150 \mathrm{ml}$ concentrated nitric acid. To this solution was added $2.81 \mathrm{~g}$ ascorbic acid followed by the addition in sequence of 9.40 $\mathrm{ml}$ ammonium hydroxide (sp. gr. 0.9), $5.40 \mathrm{ml} 10 \%$ bismuth nitrate $\left[\mathrm{Bi}\left(\mathrm{NO}_{3}\right)_{3} \cdot 5 \mathrm{H}_{2} \mathrm{O}\right]$ and $0.014 \mathrm{~g}$ EDTA. Finally the solution was diluted to $250 \mathrm{ml}$ with deionized water. The solution should be prepared just before use. It can be stored for $24 \mathrm{~h}$. We found that the color-developing ability of the reagent decreased with longer storage. This may be caused by the oxidation of ascorbic acid.

\section{$10 \%$ Bismuth nitrate solution}

$10.0 \mathrm{~g}$ of bismuth nitrate $\left[\mathrm{Bi}\left(\mathrm{NO}_{3}\right)_{3} \cdot 5 \mathrm{H}_{2} \mathrm{O}\right]$ was dissolved in $10 \mathrm{ml}$ concentrated nitric acid and $80 \mathrm{ml}$ deionized water.

\section{$1.2 \%(v / v)$ Triton $X-100$}

$12 \mathrm{ml}$ Triton X-100 (Carl Roth KG) was added to $400 \mathrm{ml}$ deionized water and heated in a water bath at $80^{\circ} \mathrm{C}$ for $30 \mathrm{~min}$. The solution was diluted to 1000 $\mathrm{ml}$ with deionized water after cooling. All reagents were of analytical-reagent grade.

\subsection{Procedure}

A solution containing As(III) and As(V) was injected into the ion chromatograph using a syringe when the sample injection valve was at the load position, then the instrument was run via the computer and the sample injection valve was switched to the inject position automatically. Subsequently the solution in the sample loop was eluted into the separate column, on which As(III) and As(V) in the sample were separated. After separation on the column, the As(III) and As(V) were detected by amperometric and spectrophotometric detectors, respectively. When a sample analysis was finished (the assigned run time ended), the sample injection valve was again switched to the load position automatically and the next sample could be injected.

Dilute solutions with concentrations of As(III) ranging from 12 to $200 \mu \mathrm{g} / 1$ and $\mathrm{As}(\mathrm{V})$ ranging from 40 to $400 \mu \mathrm{g} / 1$ were prepared from the primary As(III) and secondary As(V) standards. These solutions can be used for the calibration.

Known quantities of As(III) and As(V) standards were added to three of the four $50 \mathrm{ml}$ aliquots of waste water sample collected from the semiconductor industry in which no arsenic species was detected, to give concentrations of 40,80 and 120 $\mu \mathrm{g} / 1 \mathrm{As}(\mathrm{III})$ and 100, 200 and $300 \mu \mathrm{g} / 1 \mathrm{As}(\mathrm{V})$. Each solution was then injected immediately into the ion chromatograph through a $0.22 \mu \mathrm{m}$ Millipore filter which was fixed on the top of the syringe. As(III) concentrations were determined from the peak heights by the standard addition method. As(V) con- 
centrations were determined from the peak heights using the linear calibration routine of the ion chromatograph; standard As(V) solutions of three different concentrations were used for the calibration and these bracketed the concentration of the test solutions.

\section{Results and discussion}

\subsection{Electrochemical detection for As(III)}

The measurement of As(III) by polarography is well-known. We investigated the electrochemical detection of arsenite with a platinum electrode and found that the $\mathrm{pH}$ and the ionic strength of the eluent are the important factors influencing the applied potential $\left(E_{\text {app }}\right)$ and the sensitivity. When a phosphate buffer $\left(0.65 \mathrm{mM} \quad \mathrm{NaH}_{2} \mathrm{PO}_{4}-0.017 \mathrm{mM}\right.$ $\mathrm{Na}_{2} \mathrm{HPO}_{4}$, pH 5.3) was used as the eluent, the sensitivity of electrochemical detection of As(III) with a platinum electrode is very high, but this eluent did not meet the demand of sequential determination of As(III) and As(V) under our experimental conditions, because the phosphate could form the Mo-PBi heteropoly acid, as did the As(V), thus interfered with the determination of As(V). We also investigated eluents of various concentrations of sodium hydrogencarbonate-sodium carbonate containing various amounts of sodium sulfate, although the sensitivity of electrochemical detection of As(III) with a platinum electrode was high, the sulfate ion may interfere with the separation of $\mathrm{As}(\mathrm{V})$ and therefore the use of sulfate as eluent was precluded.

Fig. 2 shows the dependence of the measured peak height on the applied potential for As(III) with the eluent containing $2 \mathrm{mM}$ sodium hydrogencarbonate- $5.5 \mathrm{mM}$ sodium carbonate. The results indicate that the optimal peak height occurs at $+0.35 \mathrm{~V}$. When As(III) was detected by the electrochemical detector, part of it was oxidized to As(V) and subsequently might be detected by the spectrophotometric detector. This was proved by our experiment. At 1.5 min after the injection of sample, a small peak appeared (Fig. 6a), it was probably the peak of As(V) formed from the oxidation of As(III).

Solid electrodes are subject to complicated surface renewal problems. Oxide film formation caused

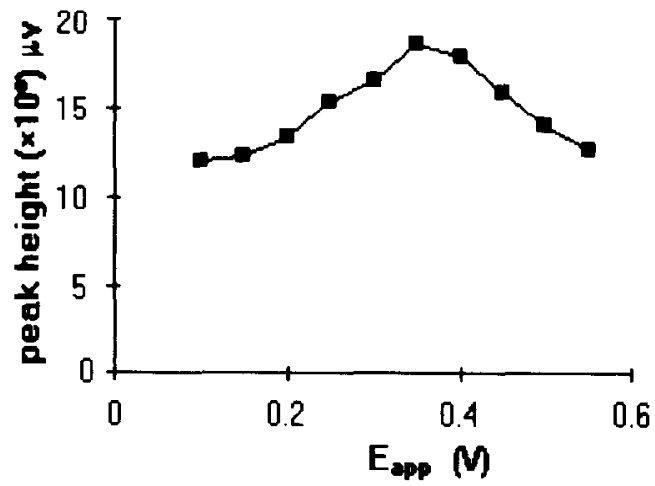

Fig. 2. Dependence of peak height on the applied potential. Eluent: $2.0 \mathrm{mM} \mathrm{NaHCO}{ }_{3}-5.5 \mathrm{mM} \mathrm{Na} \mathrm{CO}_{3}$; flow rate: 1.5 $\mathrm{ml} / \mathrm{min}$; As(III) concentration: $200 \mu \mathrm{g} / \mathrm{l}$; sample loop: $175 \mu \mathrm{l}$.

non-reproducible currents during the electrolytic oxidation of arsenic solutions [10]. To overcome this problem, the platinum electrode was occasionally cleaned by polishing with fine alumina paste.

\subsection{Spectrophotometric detection for $A s(V)$}

\section{Selection of color-developing system}

There are a number of colorimetric methods for the determination of $\mathrm{As}(\mathrm{V})$, but most of them need more than $10 \mathrm{~min}$ or require high temperature to achieve complete color developing and therefore are not suitable for use in on-line detection in IC analysis. Spectrophotometry based on the color reaction of the multi-component complexes of heteropoly acid with basic dyes have been widely used because of its high sensitivity and selectivity [23,24]. A highly sensitive and convenient spectrophotometric method based on the ion-association complex formed by heteropoly molybdoarsenic acid with ethyl rhodamine $B$ (ERB) in the presence of polyvinyl alcohol (PVA) has been reported [25,26]. This color reaction system can produce color instantaneously and may be expected to be used as a post column derivatization reaction. Unfortunately, when the system was actually used in the post column derivatization system of the VDM-II detector, the color complex formed by the reagent with As(V) adsorbed seriously on the wall of the tube and coil and a negative peak appeared. For this reason, the system was not studied further. 
To overcome the adsorption described above, we employed bismuth instead of ERB as the association cation and tested this system in the presence of surface active agent. It was found that the bismuth cation $\left(\mathrm{Bj}^{3+}\right)$ not only participated in the formation of the complex, but also accelerated the color reaction. Although this system was less sensitive than the system described above, it could develop color instantaneously at room temperature and no adsorption was encountered. Further, the blank solution was transparent and colorless. All of these features satisfied the demand of a post column derivatization reaction, so this system was suitable for $\mathrm{As}(\mathrm{V})$ detection. Possible reasons for the fast color-developing action of the Mo-As-Bi-ascorbic acid-Triton X100 system are as follows. (1) Bismuth cation may accelerate the reaction; (2) the surface active agent increased the solubility and stability of the colored complex, and precluded the hydrolysis of bismuth, as a result the speed and sensitivity of this reaction were enhanced.

\section{Influence of surface active agent}

Several surface active agents including Triton $X$ 100, Tween-80, polyvinyl alcohol (PVA) and gelatin were tested and the results are shown in Fig. 3. From the results we can see that the best surface active agent is Triton X-100, which gives the highest sensitivity at a wavclength of $700 \mathrm{~nm}$. Since surface active agent has the functions of solubilization, sensibilization, dispersion, and stabilization to the MoAs-Bi-ascorbic acid system, it is used to enhance the sensitivity of spectrophotometric detection for $\mathrm{As}(\mathrm{V})$ in the aqueous system. But we have not investigated why the enhancement factors were different from the different surface active agents examined.

When the Mo-As-Bi-ascorbic acid-Triton X100 system was used in the IC detector, the situation is quite different from that in a conventional spectrophotometric analysis, because in the former case the system is flowing under a high pressure and the eluate can reach the detector in a few seconds. This demands an even and precise addition of various reagents in a proper order to ensure color development instantaneously, so to obtain a stable baseline as well as a well-defined peak. In our preliminary experiments we tried to mix all the reagents together as a mixed color reagent. However, in this way the color development took longer. The Triton X-100 may form a thin film around the molecules of the reagents and subsequently prevent the formation of

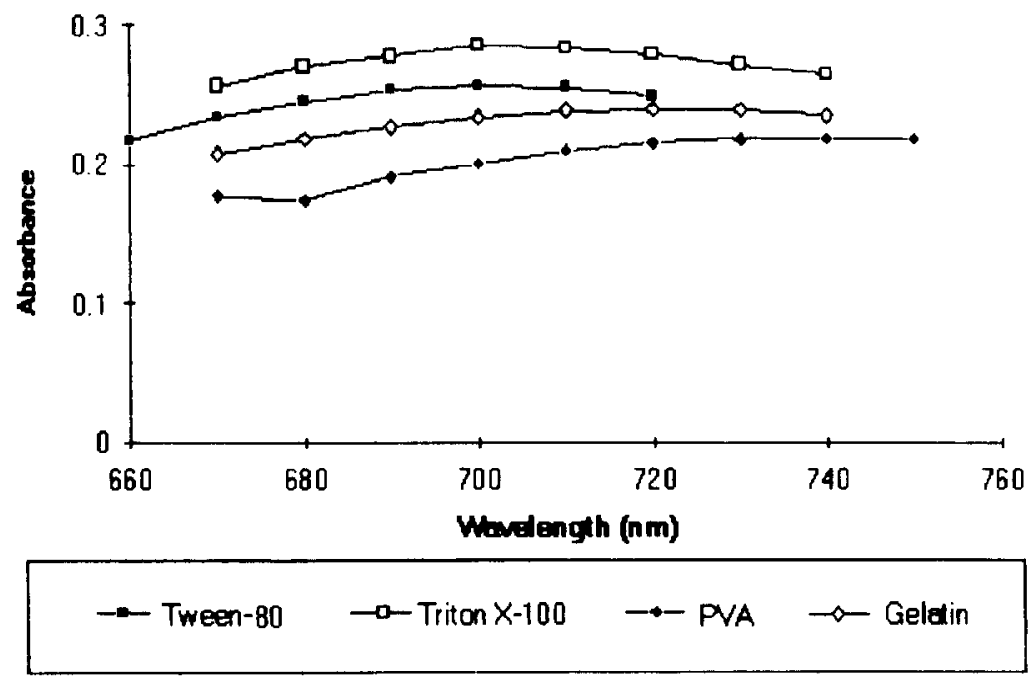

Fig. 3. Relationships between absorbance and wavelength with different surface active agents. Concentrations of As(V), ammonium molybdate, bismuth nitrate, ascorbic acid and nitric acid were $1 \mathrm{mg} / 1,0.1 \%, 0.05 \%, 0.3 \%$ and $0.35 \mathrm{M}$, respectively. Concentrations of Tween-80, Triton X-100, PVA and gelatin were all $0.04 \%$. Colorimetric measurement was performed using a Shimadzu UV-120-02 spectrophotometer with $1 \mathrm{~cm}$ quartz cells at room temperature. 
Mo-As-Bi heteropoly acid and weaken the reduction power of ascorbic acid. Further studies showed that when Triton X-100 was added after the As(V) had reacted with the ammonium molybdate-bismuth nitrate-ascorbic acid system, the color developed immediately. Therefore, a separate coil was used for the addition of Triton X-100.

At a temperature of $15-30^{\circ} \mathrm{C}$, the color of heteropoly molybdoarsenic acid took 5-15 min to develop in the absence of Triton X-100, whereas in its presence the color developed immediately and the sensitivity increased 2.8 fold. A concentration of 0.04-0.2\% was suitable, excessive amount of Triton $\mathrm{X}-100$ should be avoided due to foam formation which will interfere with $\mathrm{As}(\mathrm{V})$ determination.

\section{Acid concentration}

The optimal acid concentrations for color development were found in the range of $0.25-0.60 \mathrm{M}$ $\mathrm{HNO}_{3}$ at which the absorbance is maximum. The absorbance decreased with further increase in acid concentration. A stable color was developed in 0.35 $\mathrm{M} \mathrm{HNO}_{3}$ in the presence of $0.1 \%$ ammonium molybdate.

\section{Ascorbic acid concentration}

The ascorbic acid has no influence on the absorbance of the $\mathrm{Mo}-\mathrm{As}-\mathrm{Bi}-$ Triton $\mathrm{X}-100$ system when its concentrations vary from 0.2 to $0.4 \%$, as shown in Fig. 4. A $0.3 \%$ solution was used in all experiments.

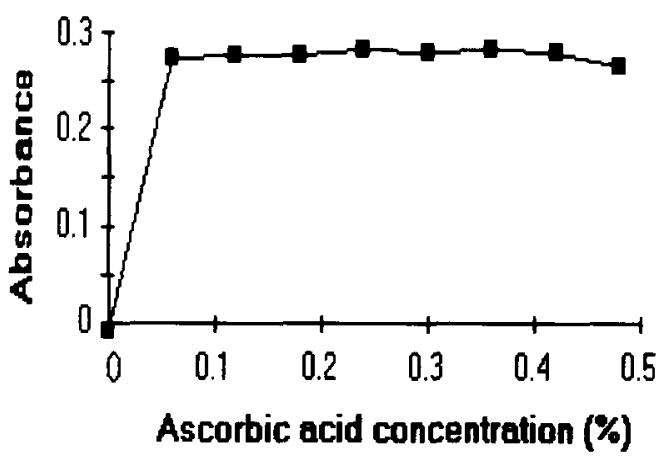

Fig. 4. Effect of ascorbic acid concentration on the absorbance. Spectrophotometric conditions: wavelength for analysis was 700 $\mathrm{nm}$; concentrations of $\mathrm{As}(\mathrm{V})$, nitric acid, ammonium molybdate, bismuth nitrate and Triton X-100 were $1 \mathrm{mg} / 1,0.35 \mathrm{M}, 0.1 \%$, $0.05 \%$ and $0.04 \%$, respectively; $1 \mathrm{~cm}$ quartz cell.

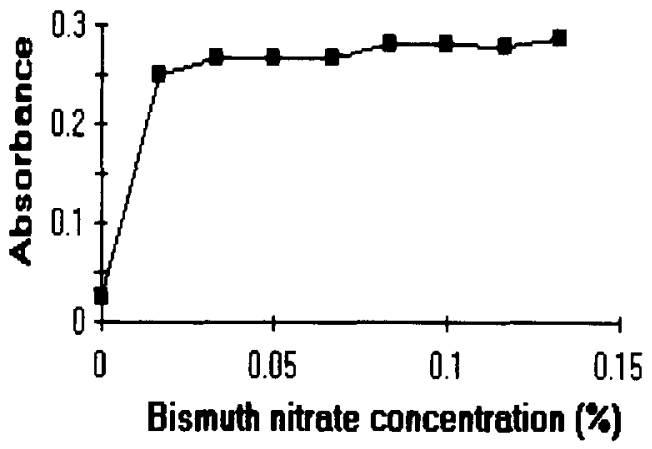

Fig. 5. Effect of bismuth nitrate concentration on the absorbance. Spectrophotometric conditions: wavelength for analysis was 700 $\mathrm{nm}$; concentrations of As(V), nitric acid, ammonium molybdate, ascorbic acid and Triton $\mathrm{X}-100$ were $1 \mathrm{mg} / 1,0.35 \mathrm{M}, 0.1 \%, 0.3 \%$ and $0.04 \%$, respectively; $1 \mathrm{~cm}$ quartz cell.

\section{Bismuth nitrate concentration}

As shown in Fig. 5, there are no obvious changes in the absorbance when the bismuth nitrate concentrations vary from 0.02 to $0.075 \%$. The absorbance increases a little with increase in the bismuth nitrate concentration, but the excessive amount of bismuth nitrate causes drifts in absorbance probably because of hydrolysis of bismuth nitrate. Therefore, a $0.05 \%$ solution was selected for all experiments.

\subsection{Chromatographic separation}

Various eluents, including $2 \%$ propanol $+50 \mathrm{mM}$ carbonate buffer [1], different concentrations of sodium hydrogen carbonate-sodium carbonate solutions [8,9,11-14], $0.01 \mathrm{M}$ orthophosphoric acid [10] and $1.8 \times 10^{-5} \mathrm{M}$ sulphuric acid [27], have been used in the determination or/and separation of As(III) and As(V) with IC or/and LC. However, they are generally unsuitable for our purpose because of different experimental conditions. By using our separation column and detection system with these eluents, some limitations were encountered. (1) As(III) and As(V) could not be separated distinctly in the presence of sulphuric acid; (2) the peak of As(V) tailed seriously and the retention time of As(V) was too long and this could result in long analysis time when the concentrations of $\mathrm{NaHCO}_{3}-$ $\mathrm{Na}_{2} \mathrm{CO}_{3}$ buffer were not optimized; (3) with orthophosphoric acid as eluent, the $\mathrm{PO}_{4}^{3-}$ interfered with the detection of As(V). We tested the various 


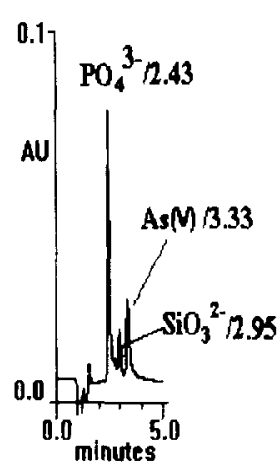

(a)
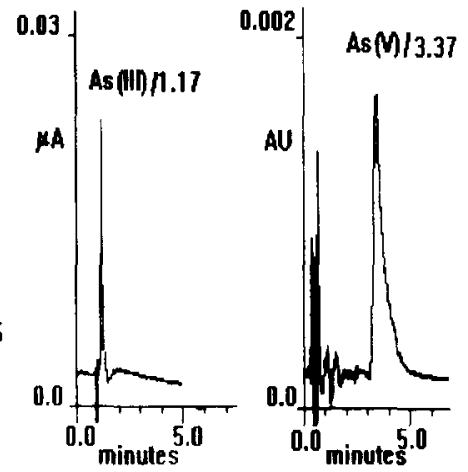

(b)
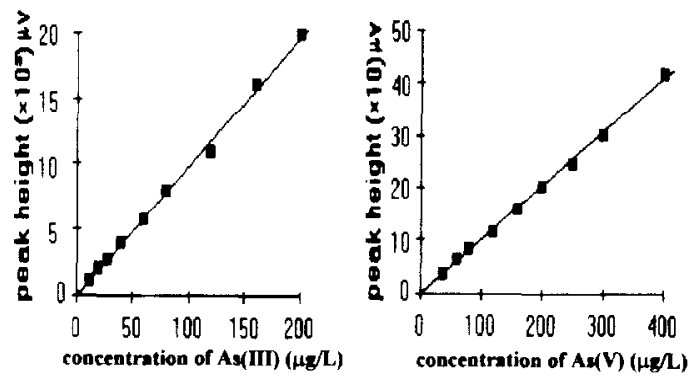

Fig. 7. Standard curves of As(III) and As(V). Eluent: $2.0 \mathrm{mM}$ $\mathrm{NaHCO}_{3}-5.5 \mathrm{mM} \mathrm{Na}_{2} \mathrm{CO}_{3}$, flow rate: $1.5 \mathrm{ml} / \mathrm{min}$, sample loop: $175 \mu 1$.

Anions that may interfere with the measurement of $\operatorname{As}(V)$ were tested. As shown in Fig. 6a, these anions involving phosphate and silicate could be separated completely on the column under our experimental conditions and therefore at least 5 times the amount of $\mathrm{PO}_{4}^{3-}$ and/or $\mathrm{SiO}_{3}^{2-}$ did not interfere with the measurement of As(V). As(III) had a shorter retention time than the anions which may have electrochemical activity under the applied potential of $+0.35 \mathrm{~V}$, as a result no interference was encountered. Fig. 6b shows that As(III) and As(V) can be separated completely on the column under our experimental conditions. The peaks at the front of the chromatogram for As(V) in Fig. 6a can be divided into two parts: the peaks before the negative peak of water and the peaks after it. The former part may be the baseline drafts caused by switching of injection valve which causes the changes in components of mobile phase and subsequently the changes in absorbance. The peak immediately following the negative peak of water is probably the peak of $\mathrm{As}(\mathrm{V})$ from the oxidation of $\mathrm{As}$ (III), as described in the section Electrochemical detection.

Table 1

Recovery of As(III) and As(V) from spiked waste water sample ${ }^{\text {a }}$

\begin{tabular}{|c|c|c|c|c|}
\hline \multicolumn{2}{|c|}{ Initial concentration $(\mu \mathrm{g} / 1)$} & \multirow{2}{*}{$\begin{array}{l}\text { Spiked concentration }(\mu \mathrm{g} / 1) \\
40\end{array}$} & \multirow{2}{*}{$\frac{\text { Found }(\mu \mathrm{g} / 1)}{39}$} & \multirow{2}{*}{$\frac{\text { Recovery }(\%)}{97.5}$} \\
\hline$\overline{\text { As(III) }}$ & N.D. ${ }^{b}$ & & & \\
\hline & & 80 & 82 & 103 \\
\hline & & 120 & 125 & 104 \\
\hline \multirow[t]{3}{*}{$\operatorname{As}(V)$} & N.D. & 100 & 98 & 98.0 \\
\hline & & 200 & 187 & 93.5 \\
\hline & & 300 & 309 & 103 \\
\hline
\end{tabular}

\footnotetext{
Mean of duplicate determinations.

b Not detected.
} 


\subsection{Standard curves, precision and accuracy}

A series of standard solutions containing $12-200$ $\mu \mathrm{g} / 1$ of $\mathrm{As}(\mathrm{III})$ and $40-400 \mu \mathrm{g} / 1$ of $\mathrm{As}(\mathrm{V})$ were analyzed, the standard curves obtained are shown in Fig. 7. The regression equations for the calibration graphs are $X=2.28+0.01 Y\left(r^{2}=0.9972\right)$ and $X$ $=6.48+0.96 Y\left(r^{2}=0.9974\right)$ for As(III) and As(V), respectively.

A standard solution containing $40 \mu \mathrm{g} / 1 \mathrm{As}(\mathrm{III})$ and $80 \mu \mathrm{g} / 1 \mathrm{As}(\mathrm{V})$ was analyzed 9 times successively under the same conditions, the relative standard deviations were found to be $3.25 \%$ for As(III) and $6.27 \%$ for As(V), respectively. The R.S.D. value of $6.27 \%$ for $\mathrm{As}(\mathrm{V})$ seems high. This may be caused by the following reasons: (1) the analog range of the output reading used is very low and thus produces larger noise, or (2) the changes in voltage and ambient temperature may cause changes in rate of reagent delivery and pressure of the pneumatic reagent delivery, subsequently affecting the color-developing reaction and resulting in higher R.S.D. values. Although the precision of the method needs to be improved further, this paper presents the most sensitive procedure for the determination of $\mathrm{As}(\mathrm{V})$ by IC with post column derivatization for the first time.

The spiked waste water samples were analyzed using the method described. The sample was injected through a $0.22 \mu \mathrm{m}$ Millipore filter to remove particles from water. Table 1 shows the recoveries of $A s(I I I)$ and $A s(V)$ from the spiked waste water samples. The recoveries of $97.5-104 \%$ for $A s(I I I)$ and 93.5-103\% for As(V) verify the accuracy of the method.

\section{Conclusions}

A procedure has been developed for the sequential determination of $\mathrm{As}(\mathrm{III})$ and $\mathrm{As}(\mathrm{V})$ in water samples with ion chromatography. The procedure employs $2.0 \mathrm{mM}$ sodium hydrogencarbonate-5.5 $\mathrm{mM}$ sodium carbonate as the eluent and amperometric electrochemical detection for As(III) coupled with spectrophotometric detection for As(V). The colordeveloping system based on the formation of MoAs-Bi heteropoly acid in the presence of Triton $\mathrm{X}-100$ avoided the interference of most common anions occurring in IC analysis. A few anions including phosphate and silicate, which may interfere with the measurement of $\mathrm{As}(\mathrm{V})$, can be separated completely on the column under the present conditions. The detection limits were $2.9 \mu \mathrm{g} / 1$ for $\mathrm{As}$ (III) and $13 \mu \mathrm{g} / 1$ for $\mathrm{As}(\mathrm{V})$, respectively. The method is simple and precise and can be applied for the speciation of $A s(I I I)$ and $A s(V)$ in waste water samples.

\section{Acknowledgements}

The authors thank the Dionex Corporation for the loan of the DX-300 chromatograph.

\section{References}

[1] B.S. Sheppard, J.A. Caruso, D.T. Heitkemper and K.A. Wolnik, Analyst, 117 (1992) 971.

[2] W. Maher and E. Butler, Appl. Organomet. Chem., 2 (1988) 191.

[3] W.R. Cullen and K.J. Reimer, Chem. Rev., 89 (1989) 713.

[4] R. Steiber and R. Merrill, Anal. Lett., 12 (A3) (1979) 273.

[5] L.D. Hansen, B.E. Richter, D.K. Rollins, J.D. Lamb and D.J. Eatough, Anal. Chem., 51 (1979) 633.

[6] T.B. Hoover and G.D. Yager, Anal. Chem., 56 (1984) 221.

[7] E.C.V. Butler, J. Chromatogr., 450 (1988) 353.

[8] L.K. Tan and J.E. Dutrizac, Anal. Chem., 57 (1985) 1027.

[9] L.K. Tan and J.E. Dutrizac, Anal. Chem., 57 (1985) 2615.

[10] L.K. Tan and J.E. Dutrizac, Anal. Chem., 58 (1986) 1383.

[11] L.K. Tan and J.E. Dutrizac, J. Chromatogr., 405 (1987) 247.

[12] C.T. Tye, S.J. Haswell, P. O"Neill and K.C.C. Bancroft, Anal. Chim. Acta, 169 (1985) 195.

[13] S. Branch, K.C.C. Bancroft, L. Ebdon and P. O'Neill, Anal. Proc., 26 (1989) 73.

[14] F.E. Brinckman, K.L. Jewett, W.P. Iverson, K.J. Irgolic, K.C. Ehrhardt and R.A. Stockton, J. Chromatogr., 191 (1980) 31.

[15] R.A. Stockton and K.J. Irgolic, Int. J. Environ. Anal. Chem., 6 (1979) 313.

[16] H.-B. Han, Y.-B. Liu, S.-F. Mou, and Z.-M. Ni, J. Anal. At. Spectrom., 8 (1993) 1085.

[17] S.B. Roychowdhury and J.A. Koropchak, Anal. Chem., 62 (1990) 484.

[18] W. D. Spall, J.G. Lynn, J.L. Andersen, J.G. Valdez and L.R. Gurley, Anal. Chem., 58 (1986) 1340.

[19] G.K.-C. Low, G.E. Batley and S.J. Buchanan, J. Chromatogr., 368 (1986) 423.

[20] W. Nisamaneepong, M. Ibrahim, W. Gilbert and J.A. Caruso, J. Chromatogr. Sci., 22 (1984) 473.

[21] D. Beauchemin, M.E. Bednas, S.S. Berman, J.W. McLaren, K.W.M. Siu and R.E. Sturgeon, Anal. Chem., 60 (1988) 2209. 
[22] J.J. Thompson and R.S. Houk, Anal. Chem., 58 (1986) 2541.

[23] S.-J. Xu, Fenxi Huaxue, 11 (1983) 312.

[24] I.P. Alimarin and E.W. Dorahova, J. Anal. Chem., 39 (1984) 965.

[25] S.-J. Xu and Y.-Z. Zhang, Fenxi Huaxue, 21 (1993) 685.
[26] X.-Z. Zhau and S.-J. Xu, Fenxi Huaxue, 15 (1987) 625.

[27] L. Ebdon, S. Hill, A.P. Walton and R.W. Ward, Analyst, 113 (1988) 1159.

[28] P. Morin, M.B. Amran, S. Favier, R. Heimburger and M. Leroy, Fresenius' J. Anal. Chem., 339 (1991) 504. 